\title{
CLAPTON UNDER LUPPEN: Analys av ett bluessolo
}

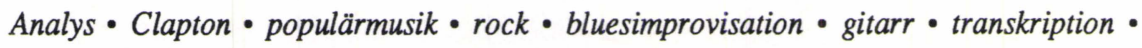
instrumental inlärning • rekonstruktion $\bullet$ fras $\bullet$ Mozarts Jupitersymfoni

Att vetenskapligt undersöka musikaliska strukturer i populärmusik är en verksamhet som tills vidare saknar traditioner så gott som helt, om man undantar t ex Philip Taggs $(1979,1981,1982)$ operationer på området. Strukturerna hos $\mathrm{t}$ ex rocklåtar har bedömts som så pass enkla, att det inte behövs vetenskaplig analys för att beskriva dem. Om man avser de strukturer som den traditionella musikvetenskapen har vant sig vid att placera i fokus, dvs harmoni och form, är uppfattningen utan tvivel riktig. Men det finns goda skäl för att närma sig saken ur en annan synvinkel.

Bennett (1980) har en kommentar beträffande tyngdpunkten i undersökningen av rockmusik som är värd att noteras i detta sammanhang:

Even the best and least prejudiced compositional analyst is making the assumption that compositions are the primary item of interest in understanding a musical culture. Undoubtedly this happens because musicologists have learned their craft in the context of the European influence, where the written score is the focus of attention within the musical culture. It is possible, though, that popular music cultures have not elevated compositions to primary importance either for players or listeners, and that attention to performance techniques (improvisational solos, for example) outweighs attention to premeditated compositional creativity. (s. 108) 
Detta innebär inte alls att improviserade solon skulle vara det enda i rocklåtar som är värt att undersöka, speciellt som det långtifrån alltid går att avgöra, om ett solo är improviserat eller förhandskomponerat. Asafjev och Tagg granskar också i huvudsak musikens färdigkomponerade beståndsdelar, den sistnämnde delvis med stöd av Asafjevs intonationsteori (jfr Zak 1982). Men det som är viktigt i Bennetts kommentar är följande: $i$ västerländsk konsertmusik är notbilden utgångspunkt för såväl uppförandet som analysen, i populärmusik spelar den en underordnad roll för båda funktionerna. Detta gör det motiverat att söka metodologiskt stöd från etnomusikologin, som ju uttryckligen arbetar med gehörstraditioner.

Som exempel på arbeten som behandlar de speciella problem, som sammanhänger med undersökning av gehörstradition, kan nämnas Lord (1960) och Nielsen (1986). På finländskt håll har området behandlats av Louhivuori (1986) och Saastamoinen (1987).

Alla dessa arbeten fäster uppmärksamhet vid två viktiga aspekter:

1) Begreppet "en riktig originalversion" är tänkbart endast om jämförelseobjektet är en detaljerad notbild som olika tolkningar baserar sig på. Det mänskliga minnet kan inte bevara musikaliska strukturer fullständigt oförändrade under längre tider. Det bör i princip vara möjligt för mänskor inom vilken kultur som helst att $i$ enskilda fall memorera och återge en sång detaljtroget $\mathrm{i}$ den bemärkelse som vi känner till. Men i kulturer där "den exakta förebilden" inte existerar finns det ingen anledning att försöka hålla fast vid en variant framom andra.

2) Alla ovannämnda skribenter för på ett eller annat sätt fram, att systematiken i improviserad musik (eller text såsom i Lords fall) avtecknar sig med hjälp av begreppsparet formel och variation.Saastamoinen talar med hänvisning till Meyers informationsteori om "regeln som flyr undan". Med detta avses att den som improviserar turvis etablerar en regel - och avviker från den.

Då det gäller instrumentalmusik med improviserade element är det dessutom intressant att undersöka spelteknikens förhållande till musiken hur olika formler utförs, hur instrumentets egenskaper påverkar formlernas gestalt etc.

I det följande kommer jag att analysera gitarrsoloandelen ur stycket "Little Girl" från LP-skivan The Bluesbreakers. John Mayall with Eric Clapton (Decca SKL 4804). Arbetsmetoden omfattar tre moment: a) transkription, b) instrumental inlärning av musiken på basen av transkriptionen och inspelningen (eftersom rock är gehörstradition är notbilden alltid ett sekundärt undersökningsobjekt vid sidan av ljudbilden) samt c) en verbal analys på basen av allt det föregående.

Transkriptionen omfattar gitarr- och sångandelarna genom hela stycket 
samt basen genom introduktionen och första strofen. Grundmodellen för trumackompanjemanget finns uppskisserat i en takt. För gitarrsolots del har jag kompletterat standardnotationen med tabulaturskrift där linjerna representerar strängar och siffrorna de band på greppbrädan där tonerna fingersätts. Tabulatursystemet har lånats som sådant från den amerikanska tidskriften Guitar Player, därifrån också symbolerna för elgitarrens specialartikulationer (böjningar etc) är hämtade.

Eftersom de fingersättningar som visas i tabulaturen är mina egna rekonstruktioner är det inte alltid fullständigt säkert att de motsvarar verkligheten. Mina bedömningar baserar sig dels på motorisk ändamålsenlighet och dels på vilka lösningar som tonmässigt kommer närmast skivans tonkvaliteter. I tveksamma fall försöker jag i detalj redogöra för a) vilka alternativ som står till buds och b) vad mina val grundar sig på.

Det bör kanske tilläggas att de fingersättningsmodeller som står som grund för analysen ingalunda grundar sig enbart på Claptons material utan också på studier i några av Claptons uttryckliga förebilder, nämligen Freddie King, Albert King, B.B. King, T-Bone Walker och Chuck Berry.

\section{Spelteknik}

Härnäst försöker jag beskriva några gitarridiomatiska sätt att framställa såkallade bluestoner. De karakteristiska bluestonerna är en ters och septim som svävar mellan stor och liten, samt en kvint som svävar mellan ren och förminskad. Dessa blå toner fås genom strängböjningar.

Bluesimprovisation på gitarr bygger på några standardlägen därifrån utvikningar göres vid behov. För att framställa dessa lägen grafiskt använder jag mig av sådana ackord- och skaldiagram som allmänt förekommer i läroböcker i gitarrspel. Diagrammen avbildar grafiskt instrumentets greppbräda; de lodräta linjerna står för strängar och de vågräta för band. Basen för standardlägena är de två vanligaste barrégreppen för molltreklanger; $t$ ex för g-moll (ex. 1).

Ur dessa ackordgrepp kan härledas vad Arlen Roth (1986 s. 130) kallar "the traditional blues 'box' scales". Numreringen i fingersättnings diagrammet korrelerar med den löpande numreringen av skalans toner. Den skala som härleds ur box a) fingersätts på följande sätt (ex. 2):

Den skala som härleds ur box b) ser ut så här (ex. 3):

Grundskalan för G-blues är alltså G-mollpentatonisk. Samma förhållande mellan tonart och skala kan generaliseras till alla tonarter.

Strängböjningar är ett centralt stildrag och tillför endel kompletteringar till tonbeståndet. Man kan uppställa tre typer: figurer på en sträng som böjs, 
a) 111

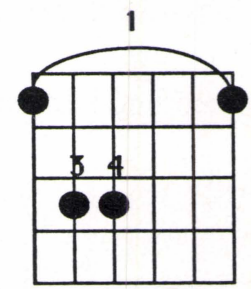

Ex. 1.

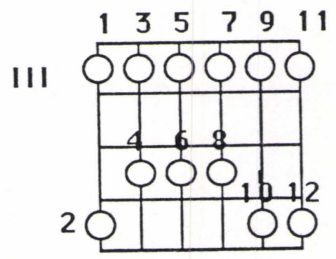

Ex. 2.

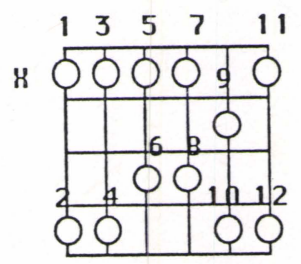

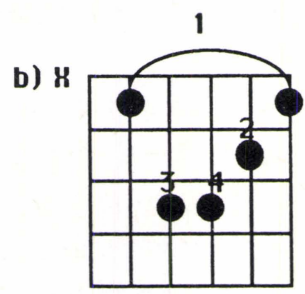

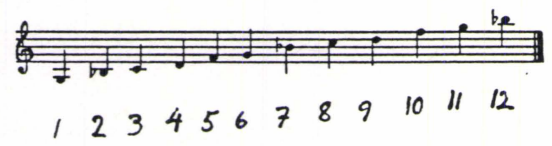


figurer på två strängar av vilka den ena böjs och figurer på två strängar vilka båda böjs. Nedan visas standardböjningarna i box a): (ex. 4)

Böjning av tonerna 7 och 12 ger tillgång till den blå tersen, ton 10 ger den blå septimen och 8 den blå kvinten. Motsvarande framställning av box b): (ex. 5)

Den blå tersen fås från tonerna 8 och 9 , den blå septimen från ton 12 och den blå kvinten från ton 10 .

Box a) och b) i kombination ger ett område på två oktaver från g1 till g3, där bluesböjningarna kan användas. Dessutom kan box a) flyttas från läge III till läge $\mathrm{XV}$, varvid hela tonsystemet höjs med en oktav och tonbeståndet utökas med den blå tersen samt kvarten i tredje oktaven. Detta är alltså det tillgängliga tonförrådet i ett G-bluesgitarrsolo.

Böjningsfigurer på två strängar av vilka en böjs förverkligas i box a) enligt följande: (ex. 6)

Böjningarna 5-5 och 8-8, från stor sekund till prim, är speciellt dissonansladdade och används följdriktigt för att ge emfas åt tonika och dominant.

Motsvarande uppställning för box b): (ex. 7)

I fortsättningen kommer jag att hänsyfta till dessa fenomen med beteckningarna 3-5, 5-5, 5-7, 5-8 och 8-8.

Böjningsfigurer där två strängar böjs samtidigt förekommer främst $\mathrm{i}$ box a): (ex. 8)

Här ingår alltså också tonartens sext, om också bara i förbigående. Som komplettering till de föregående modellerna bör nämnas en tredje, box c) (ex. 9):

Denna fingersättningsmodell ger den naturliga c-mollskalan, och i Gblues är det vanligt att man skiftar från box a, läge III, till detta läge i det skede av stycket, där harmonibakgrunden växlar till subdominant.

\section{Form}

Stycket i den följande analysen är i princip uppbyggt enligt bluesens traditionella formmönster, där varje strof är tolv takter lång och följer nedanstående formschema:

$\operatorname{rad} 1 / \mathrm{T} / \mathrm{T}(\mathrm{S}) / \mathrm{T} / \mathrm{T} /$

$\operatorname{rad} 2 / \mathrm{S} / \mathrm{S} / \mathrm{T} / \mathrm{T} /$

$\operatorname{rad} 3 / \mathrm{D} / \mathrm{S}(\mathrm{D}) / \mathrm{T} / \mathrm{T}(\mathrm{D}) /$ 

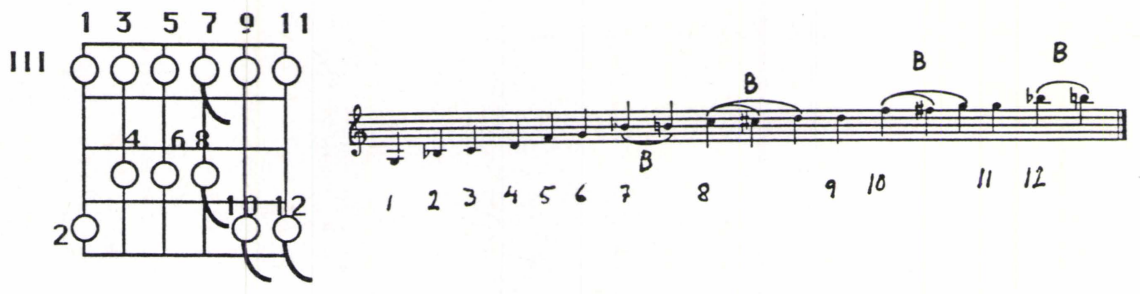

Ex. 4.
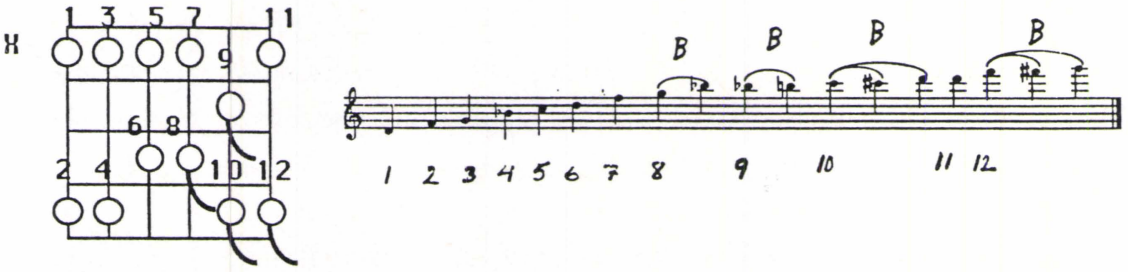

Ex. 5.

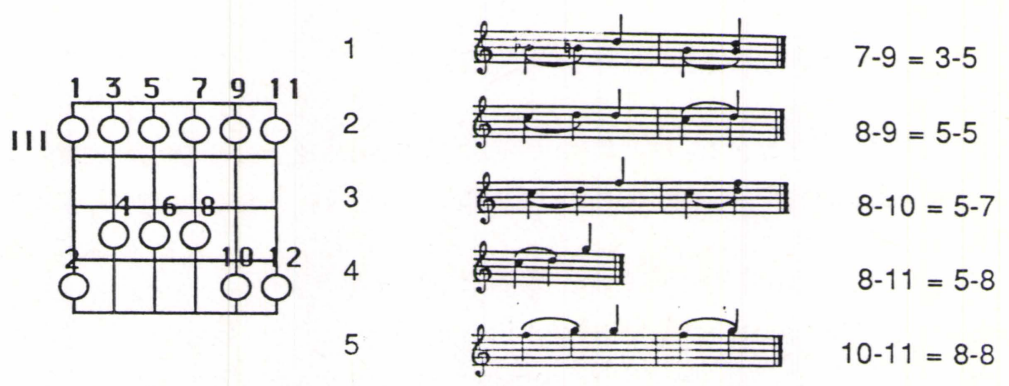

Ex. 6. 
Jeff Titon utvidgar i sin bok Early Downhome Blues (1979) analysen genom iakttagelsen att countrybluessångare från början av 1900-talet vanligen indelar varje versrad i två skilda fraser. De bokstaveras enligt följande: rad 1 fras a och b, rad 2 fras c och d samt rad 3 fras e och f. Deras normalfördelning över takterna är denna:

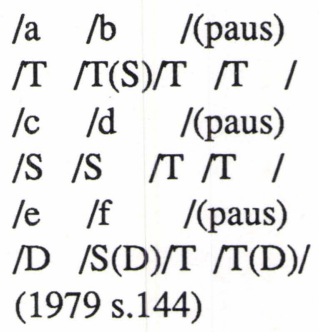

Titon gör också en iakttagelse om melodirörelsen i sjungen Downhome Blues:

Melodic motion is more frequent and more gradual in the downward direction than in the upward. The melody is likely to leap upwards and descend stepwise, pausing at the complexes on the way. (s. 156)

Med "complexes" avser Titon de tidigare nämnda svävande bluestonerna. Iakttagelsen är intressant bl a därför att många bluesgitarrister har hävdat, att de försöker imitera den mänskliga sångrösten i sina solon. Att jämföra frasindelninssätt och melodistruktur i vokal och instrumental blues är ett påtagligt sätt att undersöka tendensens allmängiltighet. Givetvis avspeglar sig sångimitationen också på andra parametrar, såsom intonation och accentuering.

\section{Analys}

Little Girl är ett rockbetonat stycke utan triolfrasering (s k beat-rytm) i tempo $1 / 4=168$. Låten är en originalkomposition av John Mayall, men dess karakteristiska riff (t ex t. 3-8) baserar sig på Howlin' Wolfs stycke Forty-four Blues (Forte 1985 s. 101). Tonaliteten är G-blues, och stycket består av fyra strofer som är 24 takter långa. Strof 3 är gitarrsolo. Vad melodi- och harmonirytmen beträffar kunde tidsvärdena ha förtätats till $1 / 8$ $=168$, varvid taktantalet per strof enligt $4 / 4$ hade blivit tolv, men accentueringen hos trummor och bas (se t. 5) avgjorde saken till förmån för det 

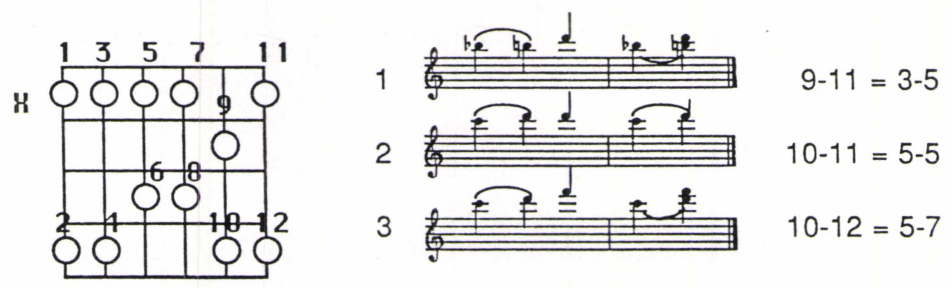

Ex. 7.

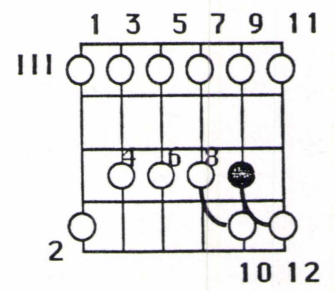

Ex. 8 .

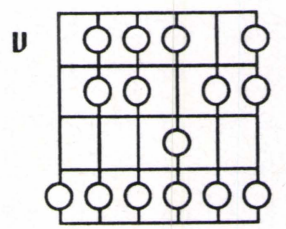

Ex. 9. 
noteringssystem som här har valts.

Harmonistrukturen är följande:

$\operatorname{rad} 1 / \mathrm{S} / \mathrm{S} / \mathrm{S} / \mathrm{S} / \mathrm{T} / \mathrm{T} / \mathrm{T} / \mathrm{T} /$

$\operatorname{rad} 2 / \mathrm{S} / \mathrm{S} / \mathrm{S} / \mathrm{S} / \mathrm{T} / \mathrm{T} / \mathrm{T} / \mathrm{T} /$

$\operatorname{rad} 3 / \mathrm{D} / \mathrm{D} / \mathrm{S} / \mathrm{S} / \mathrm{T} / \mathrm{T} / \mathrm{T} / \mathrm{T} /$

Att inleda strofen med subdominant är inte direkt vanligt men förekommer t ex i Freddy Kings instrumentallåt "The Stumble", inspelad den 5 april 1961.

Gitarrsolots inledning (t. 56-64) är förhandskomponerad att döma av den homogena helhetsgestaltningen och av den motsvarande basandelen (åttondelsindelning i t. 57-60, stegvis stigande rörelse i t. 61-63). Fingersättningen överensstämmer inte med de hittills uppställda boxmodellerna.

Det går inte att fastslå med absolut säkerhet om t. 56-64 fingersätts just så som tabulaturen visar - den stegvis stigande böjningsserien är också möjlig att göra på sträng 3 , läge XII.

Fr o $\mathrm{m} \mathrm{t}$. 64 kan man med relativ säkerhet fastslå att fingersättningen är den angivna, eftersom den enda alternativa fingersättningen för böjningsfigurerna i t. 66-68 vore läge $\mathrm{XV}$, sträng 3 och 4 enligt box a). Tonen g2 skulle i så fall spelas på sträng 4, den högsta av de tre omlindade bassträngarna. Den klara tonen och det smidiga fingervibratot på g2 i t. 65-66 tyder emellertid på att tonen spelas på någon av de tre oomlindade diskantsträngarna. I så fall är box b), läge XI enda möjligheten. För att bekvämt kunna spela den fras som börjar med de två sista noterna i t. 64 borde man redan i början av samma takt befinna sig på sträng 2 . Det är möjligt att någonstans på vägen från t. 56 till t. 64 byta från sträng 3 till 2, men det mest instrumentidiomatiska tillvägagångssättet vore att göra hela stigningen på samma sträng.

Improvisationsandelens första fras, med upptakt i t. 64 och slutande i t. 66 , kretsar kring subdominantackordets lilla septim, kvint och oktav. I melodimotivet finns en symmetri: septim + övre återgångston, kvint + nedre återgångston (t. 64-65). Septimmotivet utvidgas i t. 66 till vad jag kallar BRP-figuren (böjning av ton 10). Förkortningen syftar på termerna bend, release och pull off, dvs en kombination av böjning, uträtning och nedåtriktat legato till en sammanhängande figur. Det är fråga om en standardiserad ornamentfigur jämförbar med barockstilens ornamenteringsteknik. Den används företrädesvis för att färga nedåtriktade pentatoniska skalor som slutar på grundtonen. Frashelheten i t. 64-66 sammanfattas genom att septimen och kvinten från att ha kontrasterats mot varandra sam- 
manbinds i t. 66. I t. 67 introduceras böjningsfigur 5-7 på två strängar, dvs ton 10 böjs mot ton 12. Det polyrytmiska motiv den ingår i är karakterisktiskt för låtar i detta tempo. Den målmedvetna skalgången därifrån ned till tonikan markerar slutpunkten för skeendena så här långt. Slutpunkten nås i samma ögonblick som bakgrundsharmonin växlar från $\mathrm{S}$ till $\mathrm{T}$. Tonen g2 i t. 69 bryts naturligt $i$ ett nedåtriktat glissando när gitarristen byter läge och övergår till att bearbeta box a), läge III. Slutpunkten i t. 69 visar sig vara skenbar, den nedåtriktade rörelsen fortsätter ytterligare en oktav och slutar vid $\mathrm{g} 1$.

Manövern påminner starkt om de skenbara slut med sekvensartade nedåtriktade temautvidgningar som förekommer i den klassiska symfonilitteraturens genomföringsdelar. Jfr $\mathrm{t}$ ex den långsamma satsen i Mozarts Jupitersymfoni: i t. 32 börjar ett triolmotiv med dominantslut i t. 34 . Upprepningen startar i t. 35, och dess upplösning i tonikan uppskjuts till t. 39, där också harmonin växlar från D till T. (ex. 10)

I t. 71 stiger linjen via tvåsträngsböjningarna 5-5 och 8-8 (ton 8 böjs mot ton 9 , ton 10 böjs mot ton 11). Frasen är praktiskt taget identisk med den som inleder B.B. Kings instrumentalstycke Slidin' and Glidin' (King 1985). Utvikningen till $\mathrm{c} 3$ föranleder skifte från läge III till V, vilket $\mathrm{i}$ sin tur möjliggör de countryinfluerade dubbelgreppen med förslag i t. 72. Här formar Clapton alltså inte linjen efter lägets möjligheter, utan byter läge för att linjen "vill" uppåt. Lägesbytet följer det mönster som tidigare har presenterats under beteckningen box c).

Läge V är också placeringen för box b) i D-dur, dominanttonarten. Dominantharmoni inträder mycket riktigt i t. 73, där samma läge bibehålls. Takterna 73-76 indelas i två lika långa fraser, en över dominant- och en över subdominantharmoni, vilka sinsemellan bildar en fråga-svar -helhet. Att lägesbytet tillbaka till läge III sker just i t. 74 är inte säkert; det kan också ske i pausen som inleder t. 75. Böjningen f2-g2 och tersen b1-d2 förutsätter i vilket fall som helst läge III, box a). Böjningen i t. 77 är en utvikning från box a) och fingersätts såsom nedanstående diagram visar. (ex. 11)

T. 79 innehåller en klassisk slutformel (grundton, ters + kvint, undre dominant) som ofta återkommer hos Clapton.

En granskning av melodikurvan för detta stycke (ex. 12) visar omedelbart, att pauser mellan fraserna saknas praktiskt taget helt. Fraserna är visserligen bokstaverade på samma sätt som i Titons strofmodell, men frasindelningen i "Little Girl" visar inte mycken överensstämmelse med modellen. Eftersom rad 1 med de tänkta fraserna a och b lämnas bort, börjar bokstaveringen med c. Som ex. 12 visar, innehåller solot "för många" fraser. Fraserna $\mathrm{c}$ och $\mathrm{d}$ bildar ett normalt fraspar för rad 2. Pausen i radens 


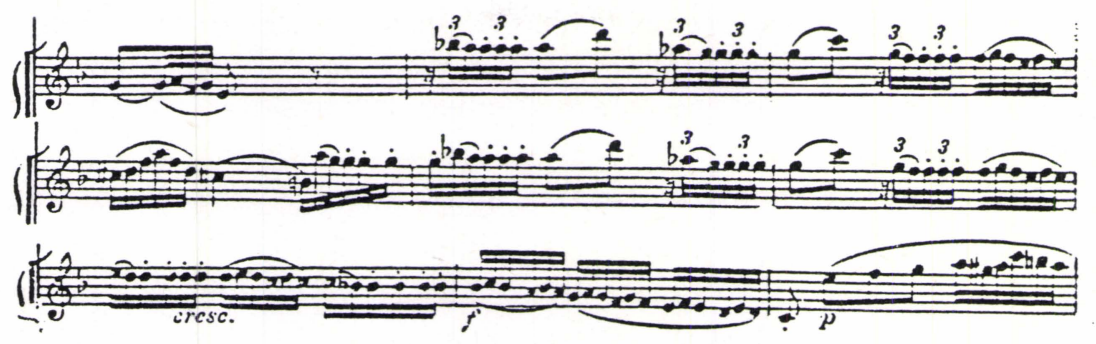

Ex. 10. Mozart: Symfoni C: K 551. Edition Eulenberg nr 401 s. 34-35.

III

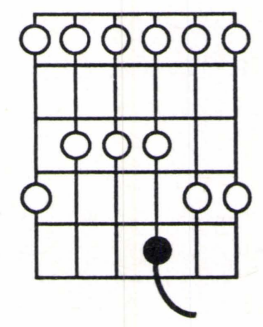

Ex. 11 .

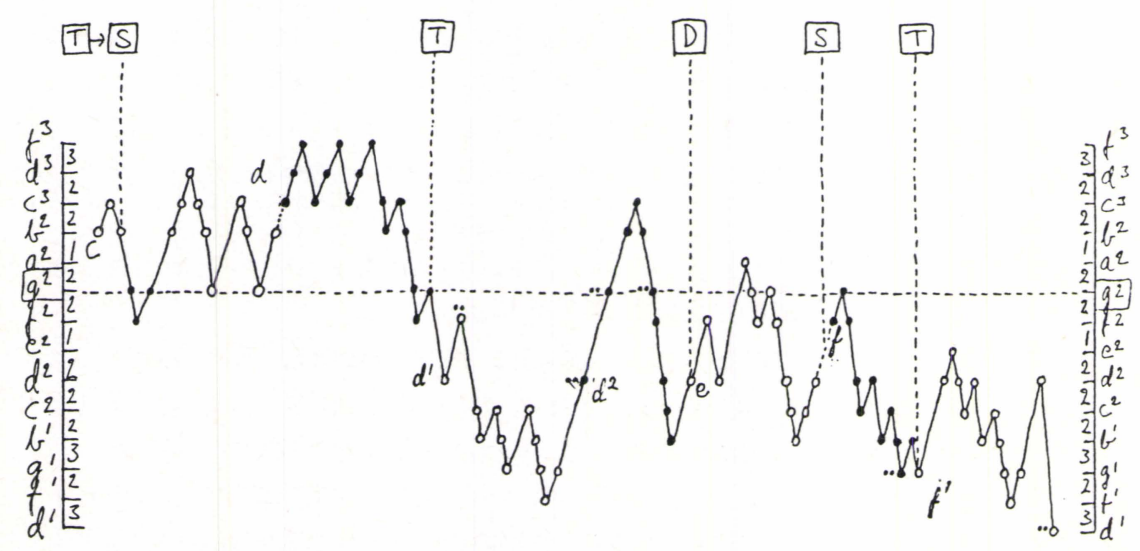

Ex. 12 . 
slut uteblir emellertid. I stället skapar solisten kontrast till det föregående genom att byta läge (och därmed oktavläge samt klangfärg) före inledandet av den fras som ersätter pausen. Här har vi alltså att göra med en teknik, där fråga/ svar -dialogen mellan sång och gitarr överförs till en och samma instrumentalstämma. Både fras $\mathrm{d} 1$ och d2 i diagrammet har funktionen av ifyllnad mellan fras d och e och får därför ingen självständig bokstavering. Fraserna e och $\mathrm{f}$ följs av f1, som motsvarar en instrumental slutfras i pausen efter Titons sångfras $f$.

En dylik dold samstämmighet mellan detta solo och en traditionell sångstrof är ingen självklarhet, men den föregående motivanalysen verkar bestyrka antagandet: fraserna c-d resp. e-f har en markant melodisk profil, medan en sådan saknas i d1-d2 resp. f1 . När solostrukturen fjärmar sig från sångstrofen som förebild i det att frasmaterialet ökar på andningspausernas bekostnad, får man anledning att indela frasmaterialet i primärt och sekundärt, eller sak och ifyllnad. (ex. 12)

Fig 2 i jämförelse med motsvarande framställningar av mer statiska R \& Bsolon visar att ju rörligare melodimaterial som framställs enligt denna skalmodell, desto mindre säger bilden om materialets rörelsetendenser. Tydligt är att den ökade rörligheten utbreder aktiviteten över ett större tonområde; man kunde också tänka sig att det ledde till ökad tonupprepning, men så sker inte. Regeln om språng uppåt och stegrörelse nedåt håller inte i detta fall. Både och förekommer åt vartdera hållet. De enda tydliga dragen i fig 2 är en markant betoning av grundton, ters och kvart samt tendens till uppåtriktade språng från grundton till kvint och frånvaro av motsvarande språng nedåt. Dessutom bekräftar figuren det tidigare antagandet att tonmaterialet i G-blues i huvudsak utgörs av den G-mollpentatoniska skalan. Också tonerna e och a förekommer, men bara enstaka gånger.

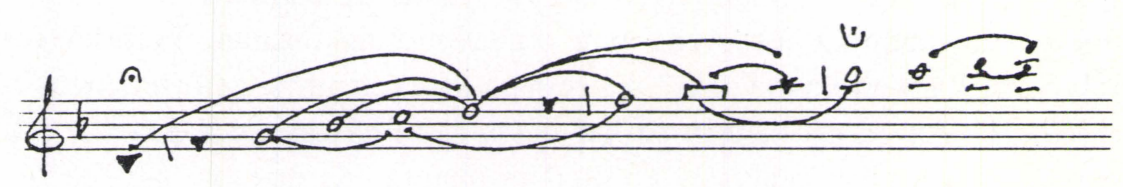

Ex. 13. 


\section{Sammanfattning}

Ur det föregående kan man utkristallisera några huvudpunkter. För det första: den harmoniska strofformen med subdominantinledning utgör en traditionell variant på bluesens standardprogression. Improvisationsdelens inledningsfras med betoning på det underliggande $S$-ackordets lilla septim är intressant. Tonen kunde också förstås som tonikans lilla ters. Fenomenet bäddar för uppfattningen att blues i grund och botten är modal musik, där melodibildningen inte nödvändigtvis påverkas av ackompanjemangets harmoniska funktioner. Som ex. 12 visar, förändras inte melodilinjens tonala tyngdpunkter nämnvärt trots harmoniväxlingarna.

För det andra: skenbart finns det ingen överensstämmelse mellan frasindelningarna i detta solo och i vokal blues. En närmare granskning av frasernas natur avslöjar emellertid, att de naturligt indelar sig i sak och ifyllnad. Om man jämställer ifyllnaden med pauserna mellan en bluessångares fraser, motsvarar det återstående materialet precis de sjungna fraserna.

Solon i framför allt långsamma bluesstycken presenterar ofta dramatiska kontraster mellan emotionell spänning och vilotillstånd. Det förra tar sig t ex uttryck i maximal tonhöjd, tonupprepning och förglesning av tidsvärden i klimaxpunkten. Det senare signaleras t ex genom nedåtriktade pentatoniska skalor utan betoning av enskilda toner. I "Little Girl", som är en snabb danslåt, spelar kontraster av detta slag en underordnad roll vid sidan av den kontinuerliga metriska energin.

Standardiserade inlednings- och avslutningsformler hör till saken i bluesbesläktade solon oavsett tempo. Uttryckt med Meyers (1969) terminologi är redundansen stor i början och i slutet, medan informationsvärdet ökar i mitten. Inledningsfrasens uppgift verkar vara att påkalla lyssnarens uppmärksamhet på vad som följer, medan slutfrasen tydligen signalerar att lyssnaren får överföra uppmärksamheten till något annat, vanligtvis sången.

Av återkommande formler i bluesgitarrspel kan man uppställa åtminstone följande typer: inledningsformler, avslutningsformler, formler för emotionell spänning resp. vila och ornamenteringsformler. Formler för polyrytmisk effekt kunde också ses som en kategori för sig (jfr tersmotivet i t. 67-68). Att gå närmare in på hur dessa formler varieras i enskilda fall förutsätter metodisk analys av ett bredare material än det som här har behandlats.

Till slut några ord om de mest uppenbara begränsningarna med den analysmodell som här har presenterats. Det som modellen klarlägger i det undersökta materialet inskränker sig till två nivåer: dels visar den, til- 
lämpad på ett tillräckligt digert material, vilka melodiska, rytmiska och harmoniska motiv som hör till råmaterialet för soloimprovisation bland gitarrister i blues- respektive $\mathrm{R} \& \mathrm{~B}$-idiomet. Dels visar den vilka speltekniska medel som kan användas för att förverkliga figurerna i fråga. Ur den synvinkeln kan modellen ha en viss tillämpning som ett gitarrpedagogiskt hjälpmedel. Däremot tror jag inte att musikens expressiva element kan avslöjas på detta sätt. Den spelstil som bl a Clapton representerar spred sig under 1970-talet till otaliga andra gitarrister. Det finns utan tvivel en rationell förklaring till att vissa av dem tilltalar publiken mer än andra. Men att komma den förklaringen på spåren kräver ett helt annat sätt att närma sig ämnet.

\section{Källor}

Bennett, H. Stith

1980 On Becoming a Rock Musician. Amherst.

Eklund, Björn

1987 Bluesfraser hos Eric Clapton. En studie i elgitarrens spelteknik. Pro gradu -arbete vid Helsingfors universitets musikvetenskapliga institution.

Kolinski, Mieczyslaw

1961 "Classification of Tonal Structures". Studies in Ethnomusicology 1:38-76.

Kolinski, Mieczyslaw

1964 "The Structure of Melodic Movement. A New Method of Analysis". Studies in Ethnomusicology 2:95-120.

Lord, Albert

1960 The Singer of Tales. Harvard University Press.

Louhivuori, Jukka

1986 Hengellisten kansansävelmien muuttuminen. Tampereen yliopiston Kansanperinteen laitoksen Moniste 10.

Meyer, Leonard B.

1969 Music, the Arts and Ideas. Chicago.

Nielsen, Svend

1982 Stability in Musical Improvisation. A repertoire of Icelandic epic songs. Köbenhavn.

Saastamoinen, Ilpo

1987 "Kolttasaamelainen le'udd: sattuman entropiaa vai salattua järjestystä". English summary: "the leu'dd song of the skolts in Lappland: the entropy of chance or a hidden order?" Etnomusikologian vuosikirja 1986. Toim. Kurkela \& Pekkilä. Jyväskylä. 
Sargeant, Winthrop

1946 Jazz: Hot and Hybrid. New York.

Stearns, Marshall W.

1973 The Story of Jazz. New York.

Tagg, Philip

1979 Kojak - 50 seconds of television music. Gothenburg.

Tagg, Philip

1981 "Fernando the Flute". Kompendium nr 8106. Musikvetenskapliga institutionen vid Göteborgs universitet.

Tagg, Philip

1982 "Analysing popular music: theory, method and practice". Popular Music 2. Ed.

Middleton \& Horn. Cambridge University Press.

Titon, Jeff Todd

1979 Early Downhome Blues. University of Illinois Press.

Zak, Vladimir

1982 "Asaf'ev's theory of intonation and the analysis of popular song". Popular Music 2. Ed. Middleton \& Horn. Cambridge University Press.

Skivor

Guy, Buddy

1986 Buddy Guy. Chess records DLP 209

Johnson, Robert

1966 King of the Delta Blues Singers. CBS Archive Series 62456

King, Albert

1984 Laundromat Blues. Edsel Records ED 130.

King, B.B.

1985 King of the Blues Guitar. Ace Records CH 152.

King, Freddy

1985 Takin' Care of Business. Charly Records CRB 1099.

Mayall, John

1966 The Bluesbreakers. John Mayall with Eric Clapton. Decca SKL 4804.

Rush, Otis

1985 The Classic Recordings. Charly Records CRB 1107. 

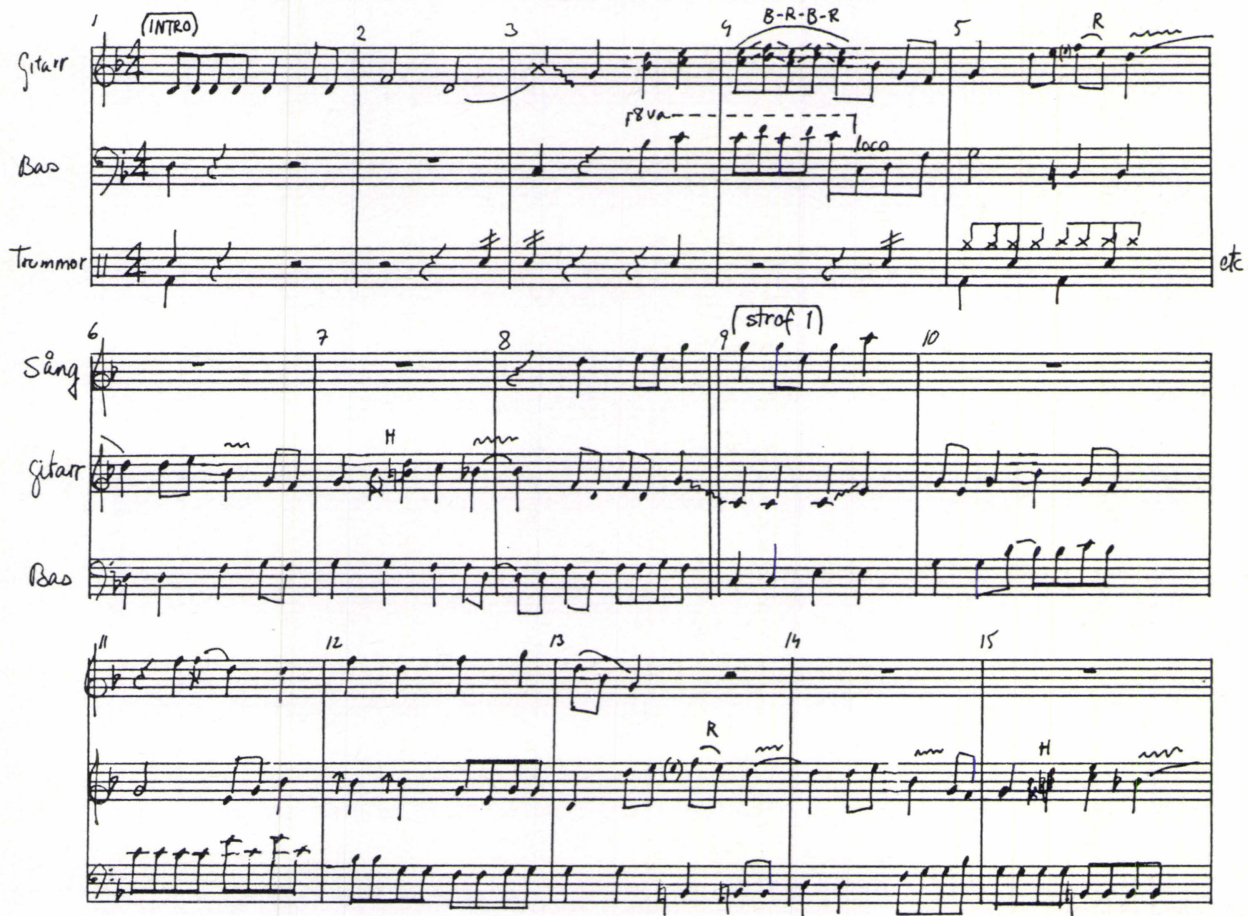

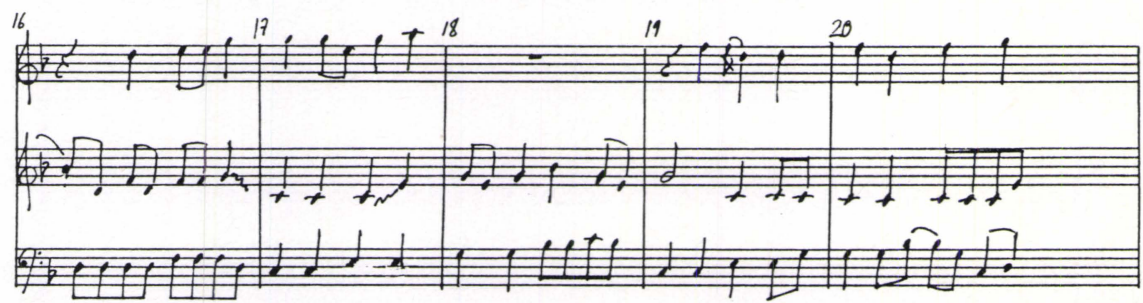

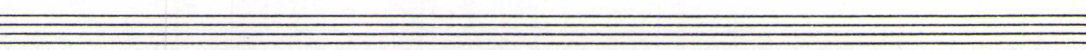



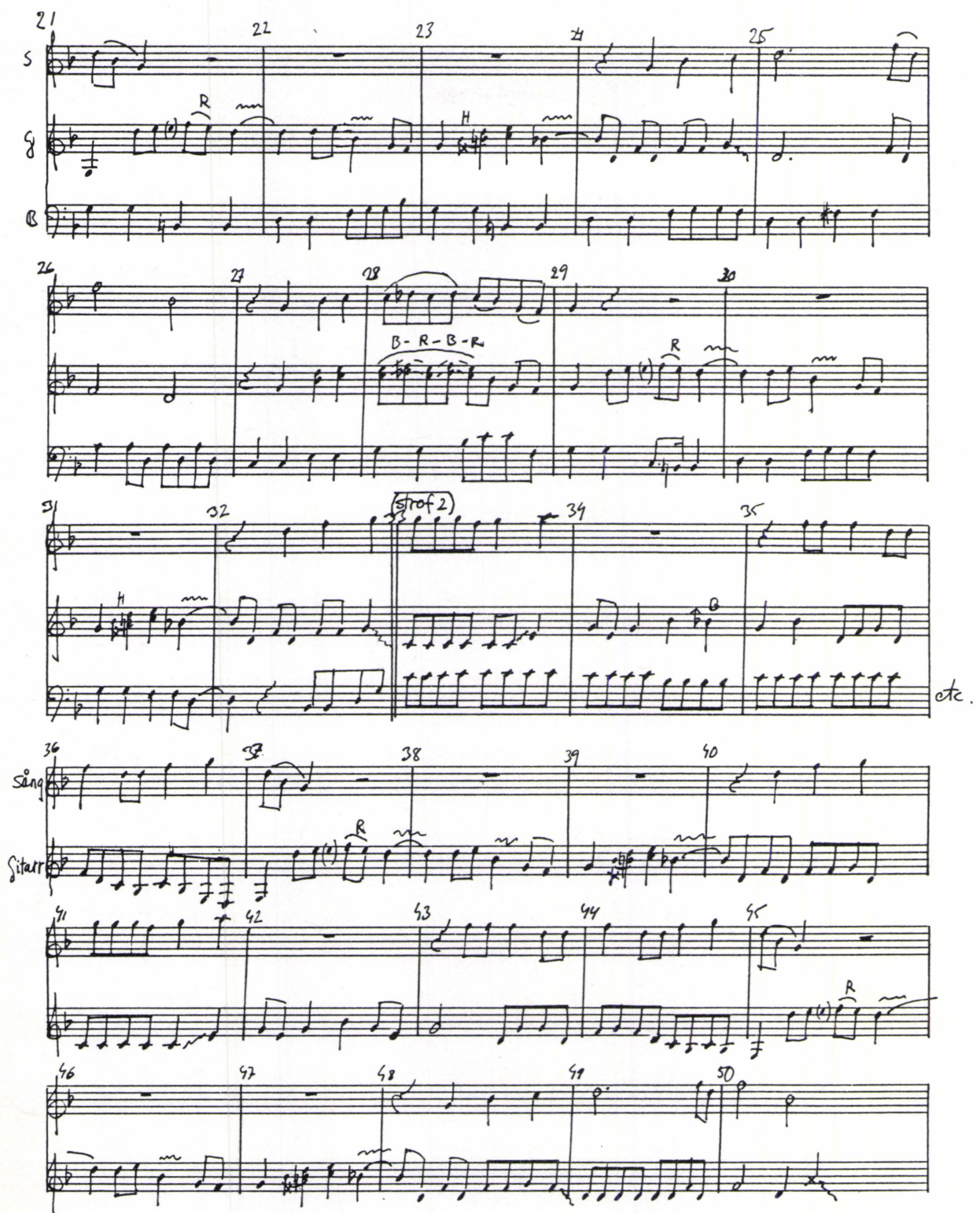
Saing

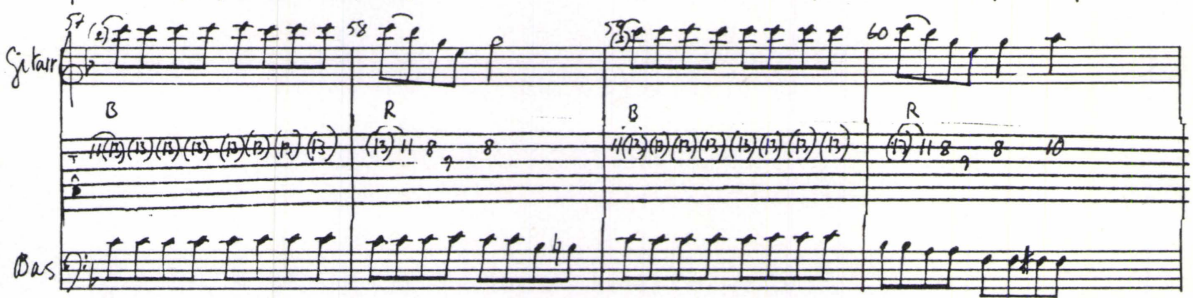

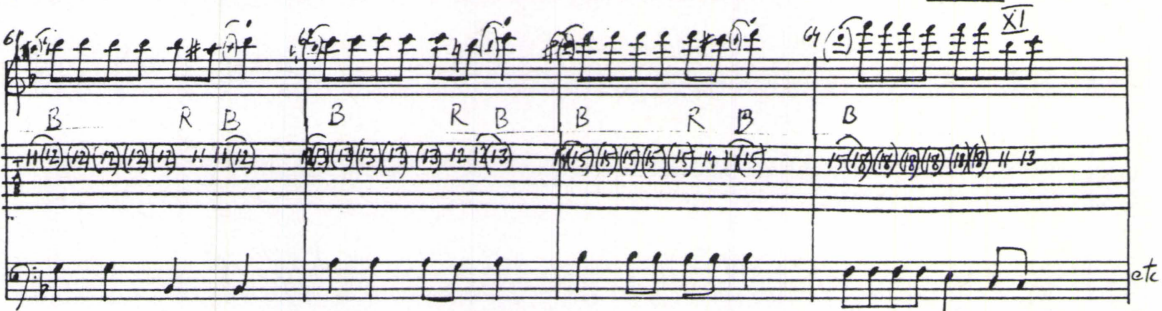

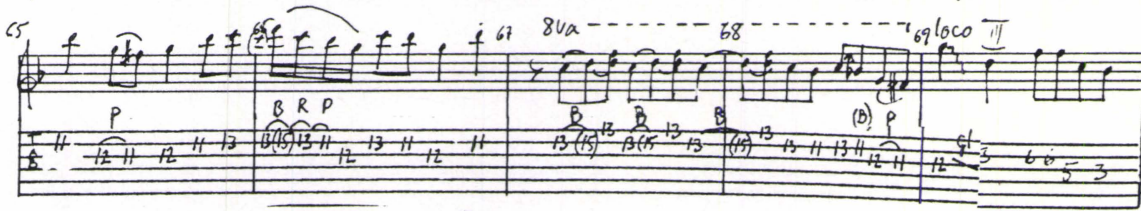

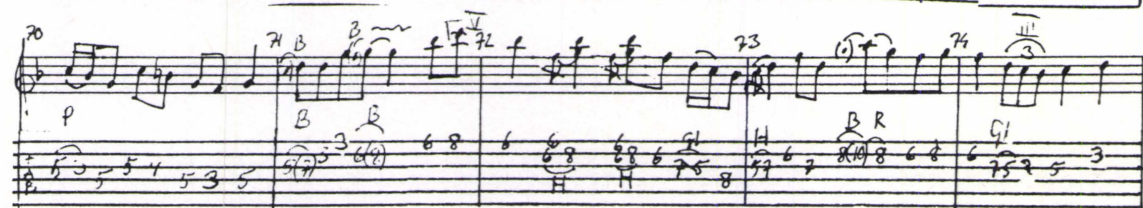

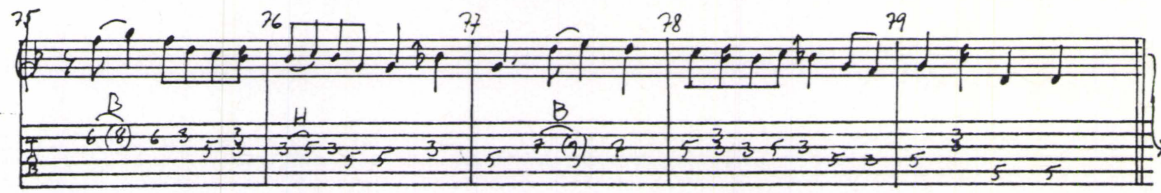
Sit. 


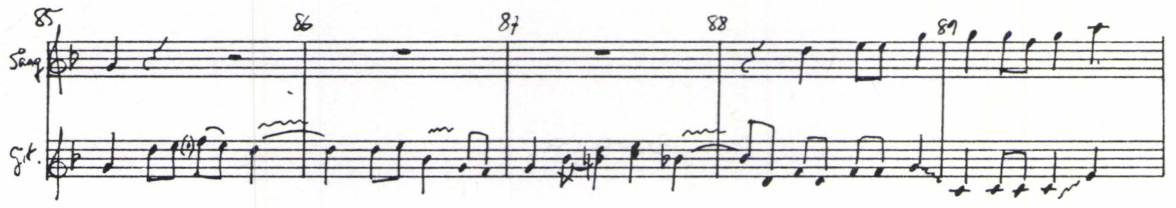

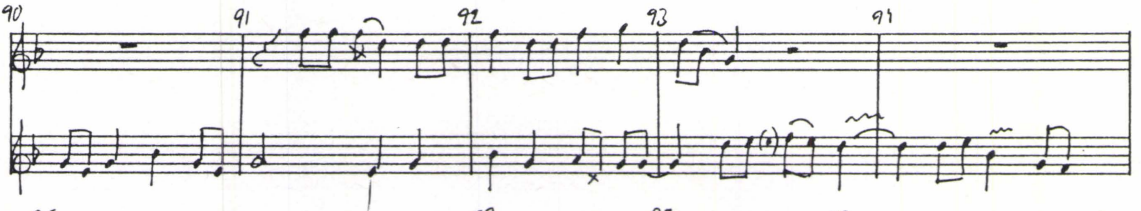
(15

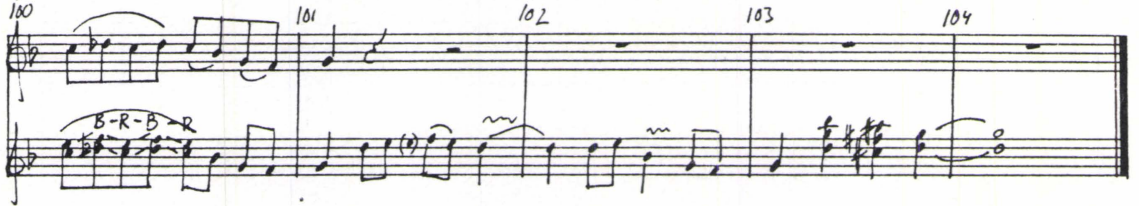


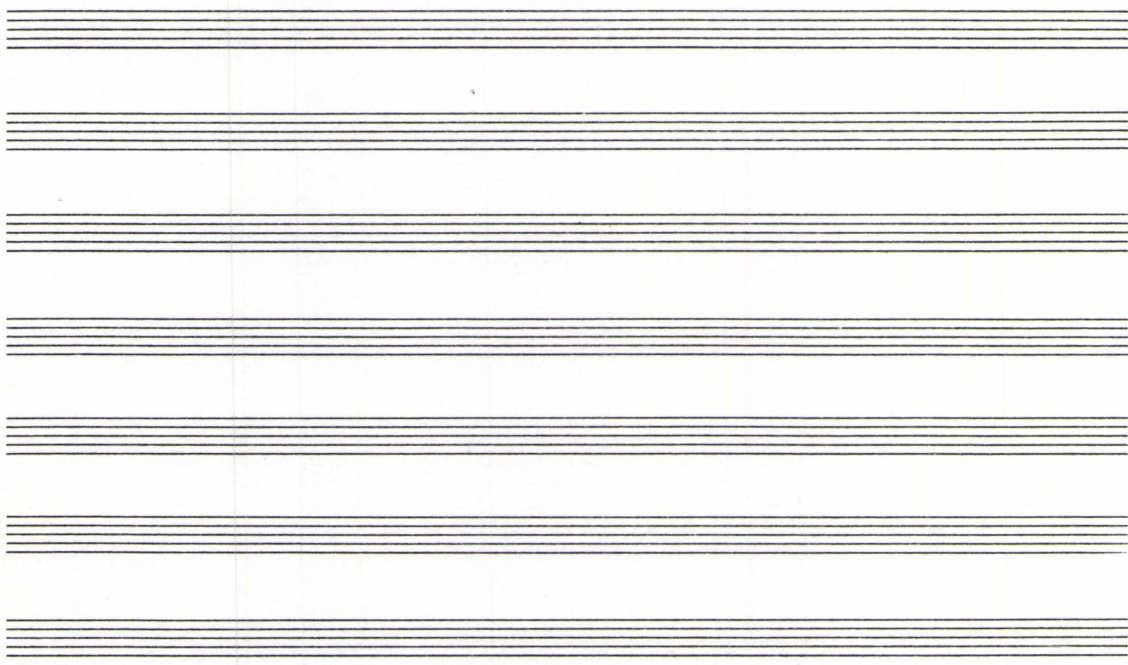




\section{Summary}

\section{Clapton under a looking glass: An analysis of a rock solo}

Musical structures in rock music have been studied very little, with the exception of the work by, for instance, Philip Tagg. The generally simple harmonic and formal structures in rock songs seldom call for an analysis in the traditional sense of the word. Because rock is oral tradition independent of notated music, methodological help may be sought from ethnomusicological works by writers such as Lord, Nielsen, Louhivuori and Saastamoinen. They emphasize two central aspects. First, the concept "a true original version" is possible only where the music exists as a detailed notation. Second, the terms formula and variation are used as a detailed notation. Besides, in regard to instrumental music with improvised elements the relation between playing technique and music is of interest.

This article presents an analysis of the guitar solo part of the song "Little Girl" from the album The Bluesbreakers. John Mayall with Eric Clapton. The work is done in three phases: (1) transcription, (2) playing of the transcribed parts on the electric guitar and (3) a verbal analysis. The solo notation has been completed with tablature showing the probable fingerings.

The playing technique is described with the help of chord and scale diagrams used in instruction books for guitar playing. The standard positions most often used in blues-based guitar playing can be deduced from them. By providing diagrams with numbers correlating to a running numbering of the notes in the scales it is possible to describe with number combinations all the strings, bendings etc. which occur in the above named standard positions.

Jeff Titon's model for chorus and phrase division is used for the description of the form. The melody structure and the scales used are illustrated with the help of the graphic models developed by Kolinski.

The main points of the verbal analysis are as follows. Firstly, the chorus form with an introductory subdominant is a traditional variant of the standard progression in blues. The introductory phrase of the improvisation part is made interesting by stressing the minor seventh of the underlying subdominant chord. Naturally, the note could also be understood as the minor third of the tonic. This will lead us to the conclusion that blues is actually modal music where the formation of the melody doesn't need to be influenced by the harmonic functions of the accompaniment. The tonal emphasis of the melody line doesn't change despite the chord changes.

Secondly, at first there doesn't seem to be any agreement between a 
phrase division in this solo and in traditional vocal blues. A closer look at the nature of the phrases reveals, however, that they divide into matter and fill in quite naturally. If a parallel is drawn between the "fill in" and the rests between the phrases of a blues singer, the remaining material corresponds exactly to the sung phrases.

Especially in slow blues the solos often show dramatical contrasts between emotional tension and rest. The former is expressed e.g. by maximal pitch, note repetition and augmentation of the time values during climax. The latter is signalled, for example, by descending pentatonic scales without stressing of individual notes. In "Little Girl", a fast dance tune, contrasts like this play a minor role beside the continuing metrical energy.

Typically, standardized introductory and ending formulas belong to blues related solos irrespectively of tempo. As Meyer would have said, the redundancy is great at the beginning and in the end while the amount of information increases in the middle. The role of the introductory phrase seems to be to attract the listener to attend to what follows, whereas the ending phrase obviously signals to the listener that he can turn his attention to something else, usually the vocal part.

At least the following types of recurrent formulas can be found in blues guitar playing: introductory formulas, ending formulas, formulas for emotional tension and rest and ornamental formulas. Formulas for polyrhythmic effect could also be seen as a category of their own (cf. the third motive in measures 67-68). A more detailed study of the variation of the formulas in individual cases would require a methodological analysis of a larger material than the one used here. 